\title{
CLINICAL PROFILE OF DIABETIC FOOT ULCERS OF PATIENTS ATTENDING SURGICAL OPD IN RURAL MEDICAL COLLEGE
}

\author{
Sanjeev Singla ${ }^{1}$, Sundeep Singla ${ }^{2}$, Mamta Singla 3 , Gaurav Thami ${ }^{4}$, Pushpinder Mallik ${ }^{5}$, Deepak ${ }^{6}$, Nivesh Aggarwal7, M. K Garg ${ }^{8}$ \\ ${ }^{1}$ Associate Professor, Department of Surgery, BPS Government Medical College, Khanpur Kalan, Sonepat. \\ ${ }^{2}$ Assistant Professor, Department of Medicine, Rajshree Medical Research Institute, Bareilly. \\ 3 Professor, Department of Surgery, Muzaffarnagar Medical College. \\ ${ }^{4}$ Assistant Professor, Department of Surgery, BPS Government Medical College, Khanpur Kalan, Sonepat. \\ ${ }^{5}$ Assistant Professor, Department of Surgery, BPS Government Medical College, Khanpur Kalan, Sonepat. \\ ${ }^{6}$ Assistant Professor, Department of Surgery, BPS Government Medical College, Khanpur Kalan, Sonepat. \\ 7 Professor, Department of Surgery, BPS Government Medical College, Khanpur Kalan, Sonepat. \\ ${ }^{8}$ Professor, Department of Surgery, BPS Government Medical College, Khanpur Kalan, Sonepat.
}

\section{ABSTRACT}

\section{OBJECTIVE}

To study the clinical profile of dibetic foot ulcers of patients attending surgical OPD in rural medical college.

\section{MATERIAL AND METHODS}

Clinical profile of 40 patients of diabetic foot ulcers was studied. All the patients were subjected to complete haemogram, fasting and PP blood sugar, LFT, KFT, lipid profile, urine R/E, pus c/s, colour doppler of lower limb and x-ray foot.

\section{RESULTS}

Majority of patients with diabetic foot ulcers were of age group 41-70, male, diabetes mellitus of duration more than 6 years, had intermittent claudication and single ulcer.

\section{KEYWORDS}

Diabetes, Foot, Ulcer.

HOW TO CITE THIS ARTICLE: Sanjeev Singla, Sundeep Singla, Mamta Singla, Gaurav Thami, Pushpinder Mallik, Deepak, Nivesh Aggarwal, M. K Garg. "Clinical Profile of Diabetic Foot Ulcers of Patients Attending Surgical OPD in Rural Medical College." Journal of Evolution of Medical and Dental Sciences 2015; Vol. 4, Issue 102, December 21; Page: 16736-16738,

DOI: $10.14260 /$ jemds/2015/2505

\section{INTRODUCTION}

Diabetes mellitus is a metabolic disorder associated with longterm vascular and neurological complications. Diabetic foot is one of the common complications of diabetes affecting the quality of life of patients; $20 \%$ of total diabetic population have foot problems. Foot ulcers occur in 5\%-10\% of all diabetic patients and upto $3 \%$ will have lower limb amputations during their lifetime. The overall risk for amputation is increased in diabetics 15 times beyond that for non-diabetic people. ${ }^{1}$ Diabetic foot is the end point of neuropathy and PVD and amputation is the end point of diabetic foot. In India the reported incidence is $2 \%-29 \%{ }^{2,3,4}$

Foot ulcers are cutaneous erosions characterised by a loss of epithelium that extends into or through the dermis to deeper tissues. Minor trauma often footwear related has been reported as the most frequent event leading to lower extremity ulcer and subsequent amputations.

Despite many major advances in health care delivery to patients with diabetes, foot problems contiue to extract a heavy toll on the quality of life of diabetic patients. The high morbidity and mortality, loss of working hours, expenditure associated with diabetic foot problems necessitate the need for a prompt and proper approach to foot ulcer management.

Financial or Other, Competing Interest: None.

Submission 27-11-2015, Peer Review 28-11-2015,

Acceptance 14-12-2015, Published 18-12-2015.

Corresponding Author:

Dr. Sanjeev Singla,

Associate Professor,

Department of Surgery,

BPS Govt Medical College,

Khanpur Kalan, Sonepat.

E-mail: sanjeev44@live.in

DOI:10.14260/jemds/2015/2505
New dressings such as Vaccum Assisted closure, alginates, cellulose composites, non-adherent dressings and film dressings are emerging that may improve wound care. Such dressings are designed to promote wound healing. This study is done to know the clinical profile of diabetic foot ulcers of patients attending surgical OPD of BPS Govt Medical College for Women, Khanpur Kalan, Sonepat. This shall help us in better management of diabetic foot ulcer patients.

\section{MATERIAL AND METHODS}

The prospective study was conducted at BPS Govt Medical College for Women in the Department of Surgery and includes cases of diabetic foot ulcers attending surgical OPD from 1 Dec 2013 to 1 Dec 2014.

\section{Inclusion Criteria}

Patients of 18 years or older with fasting sugar $>126 \mathrm{mg} \%$.

\section{Exclusion Criteria}

Patients on treatment with corticosteroids, immunosuppressive agents, radiation therapy and chemotherapy. After explaining the procedure and purpose of the study, written consent was taken from all the patients. All the patients were subjected to complete haemogram, fasting and PP blood sugar, LFT, KFT, lipid profile, urine R/E, pus c/s, colour doppler of lower limb and x-ray foot. 


\section{OBSERVATIONS}

\begin{tabular}{|c|c|}
\hline AGE (In years) & Sex Male Female \\
\hline$<30$ & 00 \\
\hline $30-40$ & 01 \\
\hline $41-50$ & 103 \\
\hline $51-60$ & 53 \\
\hline $61-70$ & 75 \\
\hline $71-80$ & 42 \\
\hline TOTAL & 2614 \\
\hline \multicolumn{2}{|c|}{ Table 1: Age and Sex Distribution } \\
\hline
\end{tabular}

\begin{tabular}{|c|c|}
\hline Duration of Diabetes (In years) & No. of Patients \\
\hline Diagnosed for 1st time $^{\text {st }}$ & 6 \\
\hline Upto 5 & 6 \\
\hline $6-8$ & 15 \\
\hline $9-15$ & 7 \\
\hline $16-20$ & 3 \\
\hline$>20$ & 3 \\
\hline Total & $\mathbf{4 0}$ \\
\hline \multicolumn{2}{|c|}{ Table 2: Duration of Diabetes Mellitus } \\
\hline
\end{tabular}

\begin{tabular}{|c|c|}
\hline Intermittent Claudication & No. of Patients with IC \\
\hline PRESENT & 30 \\
ABSENT & 10 \\
\hline GRADE I & 6 \\
II & 16 \\
III & 8 \\
\hline \multicolumn{2}{|c|}{ Table 3: Pain and Intermittent Claudication } \\
\hline
\end{tabular}

\begin{tabular}{|c|c|c|c|}
\hline SEX & $\begin{array}{c}\text { No. of } \\
\text { Patients }\end{array}$ & $\begin{array}{c}\text { Single } \\
\text { Ulcer }\end{array}$ & $\begin{array}{c}\text { Multiple } \\
\text { Ulcer }\end{array}$ \\
\hline MALE & 27 & 23 & 4 \\
\hline FEMALE & 13 & 11 & 2 \\
\hline TOTAL & $\mathbf{4 0}$ & $\mathbf{3 4}$ & $\mathbf{6}$ \\
\hline
\end{tabular}

\begin{tabular}{|c|c|}
\hline LOCATION OF ULCER/SITE & TOTAL \\
\hline TOES & 16 \\
\hline MALLEOLUS & 6 \\
\hline DORSUM OF FOOT & 8 \\
\hline HEEL & 5 \\
\hline METATARSAL JOINT & 9 \\
\hline LATERAL ASPECT OF FOOT & 2 \\
\hline Table 4: Ulcer Location, Number and Sex Distribution \\
\hline
\end{tabular}

\begin{tabular}{|c|c|}
\hline $\begin{array}{c}\text { FASTING BLOOD SUGAR } \\
\text { LEVEL (mg\%) }\end{array}$ & No. of Patients \\
\hline$<126$ & 7 \\
\hline $126-150$ & 11 \\
\hline $151-250$ & 16 \\
\hline $251-350$ & 6 \\
\hline$>350$ & 0 \\
\hline TOTAL & 40 \\
\hline POSTPRANDIAL & 20 \\
\hline$<200$ & 8 \\
\hline $200-250$ & 10 \\
\hline $251-350$ & 2 \\
\hline$>350$ & $\mathbf{4 0}$ \\
\hline \multicolumn{2}{|c|}{ T0TAL } \\
\hline
\end{tabular}

\section{DISCUSSION}

The present study was done in the Department of Surgery, BPS Govt Medical College, for woman during the period between $1^{\text {st }}$ Dec 2013 - $1^{\text {st }}$ Dec 2014. Patients were 18 years or older with a diabetic foot ulcer of at least 30 days' duration.

\section{Age and Sex Distribution}

There were total 40 patients, which showed predominant age group affected between 41-70; 33 patients were between 4170 age group. Reiber GE et al. ${ }^{5}$ have reported similar findings in their study. They reported that among hospital discharges presenting with diabetic foot ulcers during 1983-1990, the highest percentage was in persons aged 45-64 years.

In our study out of 40 patients, 26 were male and 14 were female. According to Sussman KE. ${ }^{6}$ males are more affected than females by diabetic foot.

\section{Duration of Diabetes Mellitus}

The duration of diabetes as a risk factor has been reported by Keidlig NR, Root HF and Marble A et al. ${ }^{7}$ In our study high incidence of diabetic foot was seen in the patients with the previous history of DM for more than 6 years. The appearance of diabetic foot occurred earlier in the present study. This could be due to late detection of hyperglycaemia and due to the fact that Indians in rural population visit hospital when disease had already progressed.

\section{Intermittent Claudication}

In the present study out of 40 patients, $30(75 \%)$ patients presented with intermittent claudication. Rest pain was complained by $4(10 \%)$ patients out of 40 patients. According to Garcia M, McNamara, Gorden J, Kannel WB, et al. ${ }^{8}$ intermittent claudication is a classical symptom occuring more commonly in the diabetic subjects. A study by Rayman G, Hanan A, Tooke JE, et al. ${ }^{9}$ suggests that postural control of blood flow to the foot is disturbed in patients with diabetic neuropathy. This disturbance leads to the loss of sympathetic vascular tone. This results in hypoperfusion leading to rest pain.

\section{Ulcer and Grade of Ulcer}

In this study, 34 patients out of 40 presented with single ulcer and 6 presented with multiple ulcers. All the multiple ulcers patients had 2 ulcers each. The incidence of multiple ulcers was $15 \%$ in this study, which is similar to the incidence as reported by Reiber GE et al. ${ }^{5}$

Ellenberg M.10 found that the $90 \%$ of diabetic ulcers occurred under the pressure bearing areas of the foot and further showed that these ulcers occurred at the sites of maximal vertical force. The location of foot ulcer is determined by the site of trauma and consequence of diabetic foot pathophysiology. Edmonds ME. ${ }^{11}$ has reported that the classical position of diabetic foot ulcer is under the metatarsal heads, but it is more frequently found on the tips of the toes and occasionally on the dorsum of the toes, between the toes and on the heel. He also reported that ulcers on feet are usually circular with punched out edges. The same findings were observed in our study.

\section{Blood Sugar Level}

In this study, 33 patients had inadequate blood sugar control. According to Janke HU, Standl E and Mehnert H, et al. ${ }^{12}$ there is only a slight relationship between good control of sugar and improvement of PVD. Pirart J. ${ }^{13}$ in a study of 4400 diabetic patients over a period of 25 years stated that glycaemic control does not seem to slow the accelaration of atherosclerois.

In a series of 520 diabetic individuals, Beach KW and Strandness DE, Jr. ${ }^{14}$ found no correlation between fasting blood sugar levels, glycosylated haemoglobin and atherosclerosis obliterans. 
These findings were substantiated by University Group Diabetic Program (UDGP) study. In this study we found no significant difference in the incidence of diabetic foot, ECG changes or intermittent claudication in those patients who had better diabetic control compared to those whose blood sugar levels were less well controlled.

\section{CONCLUSION}

Age group of patients affected with diabetic foot ulcers was predominantly 41-70. Males were affected more than females. Duration of diabetes mellitus was more than 6 years in majority of patients. Intermittent claudication was found in $75 \%$ patients and rest pain in $10 \%$ patients. Single ulcer was found in $85 \%$ patients. Circular ulcers with punched out edges were found more commonly on tips of toes in weightbearing areas.

\section{BIBLIOGRAPHY}

1. Roger E Pecoraro, Gayle E Reiber, Ernest M Buegess. Pathways to diabetic limb amputation. Diabetes care 1990;13:513-521.

2. Khosla HL, Caroli RK, Bahl AL. Peripheral vascular disease in diabetes mellitus - A clinical study. Ind J Med Sci 1966;20:698.

3. Ahuja MMS, Kumar V. Diabetes mellitus in the Indian Science In: Progress in Clinical Medical (Ed.) Ahuja MMS. Arnold Hernemann New Delhi 1976.

4. Dey AB, Samal KC, Tripathy BB. Observations on diabetic foot. J Ind Med Assoc 1983;81:82-83.
5. Reiber GE, et al. The burden of diabetic foot ulcers. Am J Surg 1998;176(2):55-195.

6. Sussman KE. Juvenile type Diabetes and its complications. Springfield. 1971;348-377.

7. Keidlig NR, Root HF, Marble A. Importance of control of diabetes in the prevention of vascular complications. JAMA 1952;150:964.

8. Gracia M, McNamara P, Gordon J, et al. Cardiovascular complications in diabetes.

Adv Metas Disor 1973; Suppl.2:493-499.

9. Rayman G, Hanan A and Tooke JE. Blood flow in the stem of the foot related to positive in diabetes mellitus. Br Med J 1986;87:292.

10. Ellenberg M. Diabetic neuropathic ulcer. J Mt. Sinai Herp. 1968;35:585-594.

11. Edmonds ME. The neuropathic foot in diabetes: Part I. Blood flow. Diabetic medicine. 1986;3:111-115.

12. Janke HV, Standl E and Mehnert H. Peripheral vascular disease in diabetes mellitus and its relation to cardiovascular risk factors. Screening with Doppler ultrasound technique. Diabetes Care 1980;3:207.

13. Pirart J. Diabetes mellitus and its degenerative complications. A prospective study of 4,400 patients between 1947 and 1973. Diabetes Care 1978;1:168-88, 252-263.

14. Beach KW and Strandness BE, Jr. Arteriosclerosis obliterans and associated risk factors in insulin dependent and non-insulin dependent diabetes. Diabetes Care 1980;28:882. 